\title{
A single institution report of 19 hepatocellular carcinoma patients with bile duct tumor thrombus
}

\author{
Anon Chotirosniramit \\ Akkaphod Liwattanakun \\ Worakitti Lapisatepun \\ Wasana Ko-iam \\ Trichak Sandhu \\ Sunhawit Junrungsee \\ Division of Hepatobiliary and \\ Pancreatic Surgery, Department of \\ Surgery, Faculty of Medicine, Chiang \\ Mai University, Chiang Mai, Thailand
}

Correspondence: Sunhawit Junrungsee Division of Hepatobiliary and Pancreatic Surgery, Department of Surgery, Faculty of Medicine, Chiang Mai University, I I 0 Intavarorod, Sripoom, Chiang Mai, Thailand 50200

Tel +6653935531

Fax +66 53935532

Email sunhawit.j@cmu.ac.th
This article was published in the following Dove Press journal:

Journal of Hepatocellular Carcinoma

7 March 2017

Number of times this article has been viewed

Background: Obstructive jaundice caused due to bile duct tumor thrombus (BDTT) in a hepatocellular carcinoma (HCC) patient is an uncommon event. This study reports our clinical experiences and evaluates the outcomes of HCC patients with BDTT in a single institution.

Methods: A retrospective review of 19 HCC patients with secondary obstructive jaundice caused due to BDTT during a 15-year period was conducted.

Results: At the time of diagnosis, 14 (73.7\%) patients had obstructive jaundice. Eighteen $(94.7 \%)$ patients were preoperatively suspected of "obstruction of the bile duct". Sixteen patients $(84.2 \%)$ underwent a hepatectomy with curative intent, while two patients underwent removal of BDTT combined with biliary decompression and another patient received only palliative care as his liver reserve and general condition could not tolerate the primary tumor resection. The overall early recurrence (within 1 year) after hepatectomy occurred in more than half $(9 / 16,56.3 \%)$ of our patients. The 1-year survival rate of patients was $75 \%(12 / 16)$. The longest disease-free survival time was $>11$ years.

Conclusion: Identification of HCC patients with obstructive jaundice is clinically important because proper treatment can offer an opportunity for a cure and favorable long-term survival.

Keywords: hepatocellular carcinoma, biliary thrombosis, hepatectomy, recurrence, survival

\section{Introduction}

Obstructive jaundice caused due to bile duct tumor thrombus (BDTT) is an uncommon event in a hepatocellular carcinoma (HCC) patient. The incidence ranges from $1 \%$ to $12.9 \%$ in autopsy and surgical specimens. ${ }^{1-6}$ Few published reports exist regarding $\mathrm{HCC}$ with obstructive jaundice caused due to BDTT, and these patients are often misdiagnosed as having cholangiocarcinoma (CCA) or choledocholithiasis., Improvement of diagnosis imaging and more awareness regarding the recognition of this type of disease will increase the incidence of a correct preoperative diagnosis and further effective treatment planning. ${ }^{1-3,8-11}$ Thailand has a high incidence of HCC and liver cirrhosis. ${ }^{12}$ In this study, we summarize our clinical experiences and evaluate the results of different treatment modalities of 19 cases of this type of HCC during the past 15 years in a single high-volume institution in the north of Thailand.

\section{Materials and methods Population and clinical features}

From 2001 to 2015, a total of 407 HCC patients underwent hepatic resection at the Hepatobiliary and Pancreas Unit, Department of Surgery, Chiang Mai University 
Hospital, Chiang Mai, Thailand. We reviewed the medical records of these 19 patients, and $4.7 \%$ were found to have v. The patients' consent to review the medical record was requested, and all patient consents were received. The Faculty of Medicine, Chiang Mai University Institutional Review Board, approved the study. Fifteen patients were male and four were female with the mean age of $51.1 \pm 11.5$ years (range $35-76$ years). The diagnosis of HCC with BDTT was made from the histopathological examination of the tumor thrombi in the 16 patients who had undergone curative hepatic resection (Figure 1) and two patients who had undergone palliative choledochotomy to remove BDTT with a biliary drainage procedure. Nonsurgical treatment was performed only in one patient who was initially diagnosed with HCC and BDTT from computed tomography (CT) of the abdomen (Figure 2), concurrent

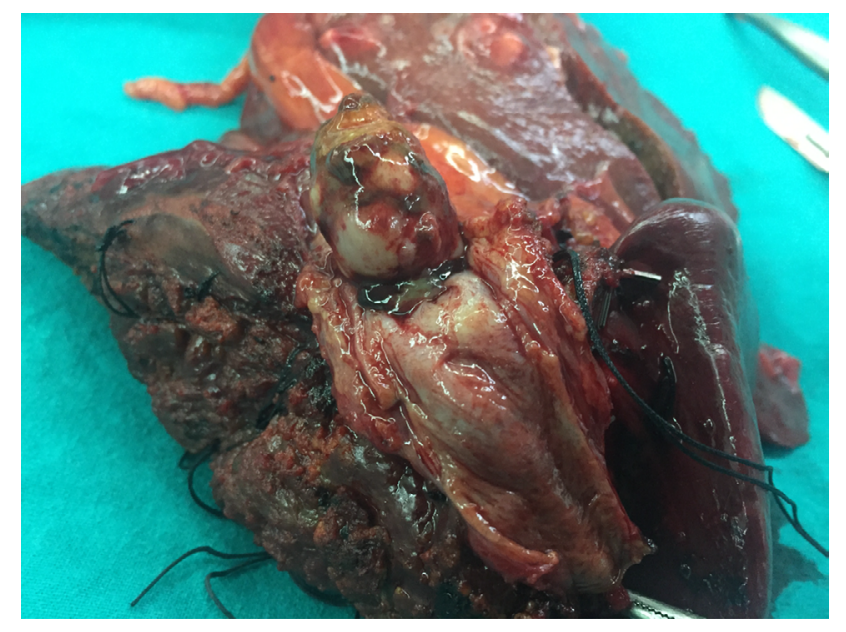

Figure I Macroscopic HCC with tumor thrombi in bile duct. Abbreviation: HCC, hepatocellular carcinoma.

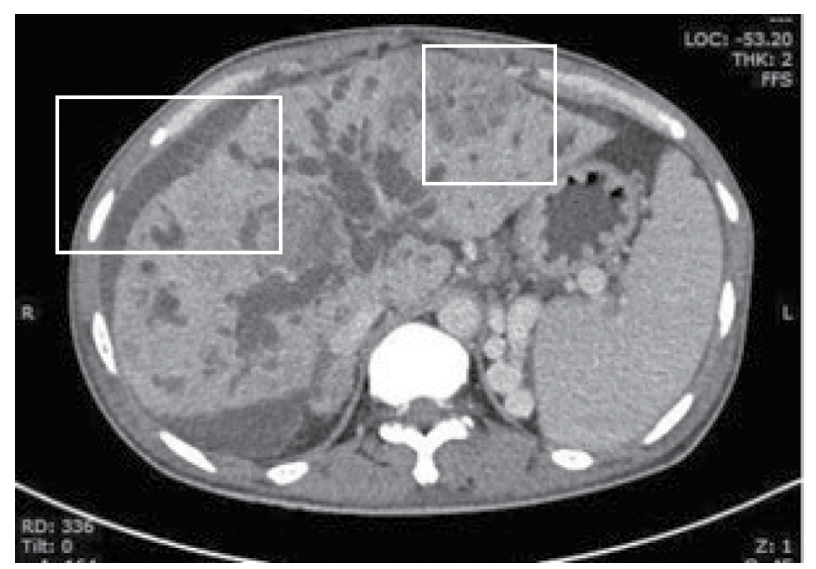

Figure 2 Cirrhosis with ascites.

Notes: HCC at Segment (large square) 8 with diffuse dilation of bile duct and intraluminal tumor thrombus; HCC also seen at Segment 3 (small square). This patient underwent nonsurgical treatment.

Abbreviation: HCC, hepatocellular carcinoma. with the evidence of an elevated serum alpha-fetoprotein (AFP) level $>950 \mathrm{IU} / \mathrm{mL}$.

Chronic hepatitis B virus (HBV) infection plays an important role in HCC development in our patients and was present in $16(84.2 \%)$ patients. Six patients received antiviral medication before surgery, and the remaining were treated after surgery. Two hepatitis $\mathrm{C}$ virus (HCV)-infected patients could not be treated with anti-HCV medication because of their health insurance coverage. The pathologically proven presence of cirrhosis was found in $12(63.2 \%)$ patients. Serum AFP $>20 \mathrm{ng} / \mathrm{mL}$ was present in $15(78.9 \%)$ patients. The remaining patients had only epigastric pain $(n=3)$, right upper quadrant mass $(n=1)$, or were asymptomatic $(n=1)$. One patient had a history of preoperative transcatheter arterial chemoembolization (TACE) because initially he refused surgical treatment. The clinical and laboratory features of all 19 patients are shown in Table 1.

Table I Clinical features of 19 patients with HCC and BDTT

\begin{tabular}{|c|c|}
\hline Characteristics & Values, n (\%) \\
\hline \multicolumn{2}{|l|}{ Demographics ( $N=19)$} \\
\hline Sex, male:female & $15: 4$ \\
\hline Age (years) (mean $\pm S D)$ & $51.1 \pm 11.5$ \\
\hline \multicolumn{2}{|l|}{ Background liver disease } \\
\hline Chronic HBV infection & $16(84.2 \%)$ \\
\hline Chronic HCV infection & $\mathrm{I}(5.3 \%)$ \\
\hline Chronic HBV and HCV co-infection & I (5.3\%) \\
\hline Non-viral (alcoholic) & I (5.3\%) \\
\hline Cirrhosis & $12(63.2 \%)$ \\
\hline \multicolumn{2}{|l|}{ Serum AFP } \\
\hline$>20 \mathrm{ng} / \mathrm{mL}$ & 15 (78.9\%) \\
\hline$\leq 20 \mathrm{ng} / \mathrm{mL}$ & $4(21.1 \%)$ \\
\hline Median (range), $\mathrm{ng} / \mathrm{mL}$ & $347.4(0.5-50000)$ \\
\hline \multicolumn{2}{|l|}{ CA $19-9$} \\
\hline Median (range), U/mL & $53.2(2-288 I)$ \\
\hline \multicolumn{2}{|l|}{ Initial total bilirubin } \\
\hline Median (range), mg/dL & $9.2(0.5-26.3)$ \\
\hline \multicolumn{2}{|l|}{ Medical history } \\
\hline HIV Infection & $2(10.5 \%)$ \\
\hline Hypertension/dyslipidemia & $3(15.8 \%)$ \\
\hline Chronic kidney disease & $2(10.5 \%)$ \\
\hline Chronic alcohol drinking & $5(26.3 \%)$ \\
\hline \multicolumn{2}{|l|}{ Obstructive jaundice/cholangitis } \\
\hline Presence & $14(73.7 \%)$ \\
\hline Absent & $5(26.3 \%)$ \\
\hline \multicolumn{2}{|l|}{ Biliary decompression } \\
\hline PTBD & $4(21.1 \%)$ \\
\hline None & $14(78.9 \%)$ \\
\hline \multicolumn{2}{|l|}{ Preoperative $\mathrm{HCC}$ treatment } \\
\hline TACE & $\mathrm{I}(5.3 \%)$ \\
\hline None & $18(94.7 \%)$ \\
\hline
\end{tabular}

Abbreviations: $\mathrm{HCC}$, hepatocellular carcinoma; BDTT, bile duct tumor thrombus; $\mathrm{HBV}$, hepatitis B virus; HCV, hepatitis C virus; AFP, alpha-fetoprotein; CA, cancer antigen; HIV, human immunodeficiency virus; PTBD, percutaneous transhepatic biliary drainage; TACE, transcatheter arterial chemoembolization. 


\section{Diagnostic imaging procedures}

The majority of the patients in the studied groups had official reports of ultrasonography (US) of the abdomen and contrastenhanced CT of the abdomen. Magnetic resonance imaging (MRI) of the abdomen was performed in one patient with chronic renal insufficiency. The preoperative imaging studies of all patients were reviewed. Dilatations of the intrahepatic and/or extrahepatic bile ducts were seen in the imaging diagnosis of 18 (94.7\%) patients with no occurrence of clinical jaundice in five patients. The tumor thrombus had approached to confluence of the bile duct in 14 (73.6\%) patients. Seven patients also showed obvious dense tumor thrombus in the biliary tree. One case with bile duct obstruction at the confluence, with no obvious intrahepatic lesion and no rising of the serum AFP level, was misdiagnosed as hilar CCA. Only one patient had no occurrence of any preoperative jaundice or obstruction of bile duct from preoperative imaging, but diffuse biliary tumor thrombus was seen in the pathological result.

\section{Operative strategies}

Clinical obstructive jaundice or cholangitis accompanied the initial diagnosis in $14(73.7 \%)$ patients. In our series, four (21.1\%) patients achieved sufficient reduction of the jaundice preoperatively with percutaneous transhepatic biliary drainage (PTBD). No intervention for biliary decompression was performed for the remaining 15 (78.9\%) patients because of the risk of bleeding from the drainage procedure. After evaluation of liver function, 18 of 19 patients underwent surgery without any appreciable morbidity or mortality.

Operative treatments for 16 patients consisted of a curative resection of the hepatic tumor. The operability rate during this study period was $84.2 \%$ (16 from 19). Removal of the BDTT occurred with hepatic resection in eight $(50 \%)$ patients who underwent additional bile duct resection and biliary-enteric anastomosis. Four other (25\%) patients underwent a choledochotomy to remove their BDTT. No additional procedures other than hepatectomy were required for four (25\%) patients' to achieve complete removal of the BDTT. Description of surgical procedures utilized in these 16 patients is shown in Table 2. In addition, intraoperatively, one patient was found to have intrahepatic metastasis at the contralateral lobe that was not detected from the preoperative $\mathrm{CT}$ of the abdomen and underwent a palliative $\mathrm{R}_{2}$ hepatic resection.

The remaining two patients received only a choledochotomy to remove the BDTT with palliative T-tube drainage or Roux-en-Y hepaticojejunal (HJ) anastomosis because
Table 2 Extent of surgical procedures for HCC patients with BDTT

\begin{tabular}{ll}
\hline Procedure & Values \\
\hline $\begin{array}{l}\text { Hepatectomy } \\
\text { Right trisectionectomy + bile duct resection + caudate }\end{array}$ & 2 \\
resection & $\mathrm{I}$ \\
Left trisectionectomy + bile duct resection + caudate & \\
resection & $\mathrm{I}$ \\
Right hepatectomy + bile duct resection & 4 \\
Left hepatectomy + bile duct resection & 3 \\
Right hepatectomy & 4 \\
Left hepatectomy + CBD exploration to remove BDTT & $\mathrm{I}$ \\
Left hepatectomy & \\
BDTT removal & 2 \\
CBD exploration to remove BDTT and palliative biliary & \\
drainage & No operation
\end{tabular}

Abbreviations: HCC, hepatocellular carcinoma; BDTT, bile duct tumor thrombus; $\mathrm{CBD}$, common bile duct.

their liver reserve and general condition could not tolerate the primary tumor resection. The pathological results of the tumor thrombus were HCC. Another patient presented with advanced disease with concurrent cirrhosis and received only palliative care followed by TACE.

Postoperative complications occurred in seven (38.9\%) patients (Table 3). Severe complications (Clavien-Dindo grades III- $\mathrm{V}^{13}$ ) occurred in three patients, including acute renal failure requiring dialysis from day 1 to day 7 (grade IVa), intraabdominal collection requiring percutaneous drainage under local anesthesia by a radiological interventionist (grade IIIa), and transient reversible hepatic failure (grade IVa) with successfully conservative management (grade IVa). Mild complications (grades $\mathrm{I}-\mathrm{II}^{13}$ ) occurred in four patients, and all were successful managed with medical or supportive treatments, including small surgical bed collection with wound infection (grade II), bile leak at hepaticojejunostomy anastomosis (grade II), and bilateral pleural effusion in two patients (grade I). All patients tolerated the operations without deaths from complications and were discharged from the hospital in good condition. The obstructive jaundice due to BDTT was successfully relieved in each patient.

\section{Histopathological profiles}

The pathological findings of the resected specimens are summarized in Table 4. The tumor diameters ranged from 2.2 to $19 \mathrm{~cm}$ (median $5.8 \mathrm{~cm}$ ). The tumors were single nodular $(\mathrm{n}=12)$, two contiguous nodules $(\mathrm{n}=2)$, and satellite formation $(\mathrm{n}=2)$. The pathologically proven presence of cirrhosis was found in 12 (63.2\%) patients. Histologically, tumors were classified as well differentiated in four patients, 
Table 3 Operative complications, postoperative recurrence, and survival details

\begin{tabular}{|c|c|}
\hline Variables & $\begin{array}{l}\text { Values, n } \\
\text { (fraction, \%) }\end{array}$ \\
\hline Inflow occlusion time (range), minutes & $10(10-160)$ \\
\hline Operating time (minutes) (mean \pm SD) & $415.6 \pm 170.0$ \\
\hline (Range) & $(240-930)$ \\
\hline Blood loss (range), mL & $1000(100-5000)$ \\
\hline Need PRC transfusions & $7(38.9 \%)$ \\
\hline Range of PRC transfusions (Unit) & $1-10$ \\
\hline Length of stay (days) (mean \pm SD) & $13 \pm 4.9$ \\
\hline Patient need for intensive care unit & $3(16.7 \%)$ \\
\hline \multicolumn{2}{|c|}{ Postoperative complications (Clavien-Dindo grade) } \\
\hline No & II (6I.I\%) \\
\hline 1 & $2(2 / 18,11.1 \%)$ \\
\hline II & $2(2 / 18,11.1 \%)$ \\
\hline Illa & $\mathrm{I}(\mathrm{I} / \mathrm{I} 8,5.6 \%)$ \\
\hline Iva & $2(2 / 18,11.1 \%)$ \\
\hline 3-month mortality & $0(0 / 16)$ \\
\hline 6-month DFS (\%) & $11(11 / 18,61.1 \%)$ \\
\hline \multicolumn{2}{|l|}{$\mathrm{HCC}$ recurrence } \\
\hline Within 6 months & $8(8 / 18,44.4 \%)$ \\
\hline Within I year & $11(11 / 18,61.1 \%)$ \\
\hline \multicolumn{2}{|l|}{ Pattern of recurrence } \\
\hline Intrahepatic recurrence & $6(54.5 \%)$ \\
\hline Lymph node metastasis & I (9.0\%) \\
\hline Pulmonary metastasis & $3(27.3 \%)$ \\
\hline Peritoneal and bowel metastasis & I (9.0\%) \\
\hline \multicolumn{2}{|l|}{ Treatment after recurrence } \\
\hline Metastectomy & $\mathrm{I}(\mathrm{I} / \mathrm{II}, 9.0 \%)$ \\
\hline TACE/DEI & $6(6 / 11,54.5 \%)$ \\
\hline Sorafinib & $2(2 / 11,18.2 \%)$ \\
\hline \multicolumn{2}{|l|}{ Survival (n) } \\
\hline$>$ I year & $12(12 / 16,75.0 \%)$ \\
\hline$>3$ years & 6 \\
\hline$>5$ years & 5 \\
\hline$>10$ years & I \\
\hline 3-year DFS, \% (n) & $60.0 \%(6 / 10)$ \\
\hline 3 -year OS, \% (n) & $60.0 \%(6 / 10)$ \\
\hline \multicolumn{2}{|l|}{ Surgical curability from hepatic resection } \\
\hline $\mathrm{R}_{0}$ & II (68.7\%) \\
\hline $\mathrm{R}_{1} / \mathrm{R}_{2}$ & $5(31.3 \%)$ \\
\hline
\end{tabular}

Abbreviations: DFS, disease-free survival; HCC, hepatocellular carcinoma; TACE, transcatheter arterial chemoembolization; DEI, direct ethanol injection; OS, overall survival; PRC, pack red cell.

moderately differentiated in nine, and poorly differentiated in three. Microscopic vascular invasion was found in 14 (87.5\%) patients. Microscopic lymphatic invasion was found in two patients despite no detected intraoperative lymph node metastasis. Types of surgical resection after compatibility with pathological positive margins were $\mathrm{R}_{0}$ for eleven $(68.7 \%)$ patients, $R_{1}$ for four $(25 \%)$ patients, and $R_{2}$ for one $(6.3 \%)$ patient.

Apparent tumor growth in the bile duct from imaging was observed in three unresectable patients. Tumor thrombi were removed by the exploration of the common bile duct (CBD) in two patients, and viable tumor cells in the bile duct were confirmed histopathologically. The intrabiliary tumor thrombi were typically fragile with a grayish-white appearance and loosely attached to the ductal mucosa that could be easily removed from the lumen in our series.

\section{Recurrence and survival time}

Patients were followed up with US or CT abdomen at least every 3-6 months at our Outpatient Department, especially during the first 2 years. The follow-up study was conducted until February 2015 with a duration that ranged from 2 to 132 months. No patient was lost to follow-up, and all 19 patients were followed up regularly until death. In our series, there was no postoperative 3-month mortality from hepatic resection, and the 6-month disease-free survival was observed in eleven of $18(61.1 \%)$ patients.

Twelve patients were followed up over 1 year with the 1 -year survival rate of $75 \%(12 / 16)$. The patients who were followed up over 3 and 5 years were analyzed separately as a subgroup for survival. Their 3- and 5-year survival rates were $62.5 \%$ and $60 \%$, respectively (Figure 3 ). Interestingly, there were five long-term survivors ( $\geq 5$-year survival) whose longest disease-free survival time was $>11$ years. All of them were still alive up to the last follow-up visit without recurrence of cancer in our series.

The survival times for the three patients who did not undergo liver resection or received only biliary decompression were only 2,2 , and 7 months, respectively.

\section{Discussion}

Jaundice was present in $19-40 \%$ of HCC patients at the time of diagnosis and was usually associated with advanced liver cirrhosis or extensive tumor infiltration. ${ }^{7,14-17}$ Obstructive jaundice caused due to BDTT in HCC patients is an uncommon feature, being identified in only $1-5 \%$ of patients treated operatively. ${ }^{4,18-21}$ The incidence in our series was $4.7 \%$. HCC may involve the biliary tract in several different ways: tumor thrombosis, hemobilia, tumor compression, and diffuse tumor infiltration. ${ }^{16}$ As the incidence of HCC has increased, more details have been reported. ${ }^{22}$ This might be due to the improvement of diagnostic imaging strategies and more awareness toward the recognition of this condition.

Patients with HCC who manifested with obstructive jaundice from BDTT present difficult and challenging problems in differential diagnosis. A correct diagnosis of this group of patients is important, because surgical treatment may be 
Table 4 Histopathological features and outcomes in 19 HCC patients with BDTT

\begin{tabular}{|c|c|c|c|c|c|c|c|c|c|c|c|c|c|}
\hline $\begin{array}{l}\text { Patient } \\
\text { No. }\end{array}$ & $\begin{array}{l}\text { Age } \\
\text { (years) }\end{array}$ & Sex & Cirrhosis & $\begin{array}{l}\text { No. of } \\
\text { tumors }\end{array}$ & $\begin{array}{l}\text { Largest } \\
\text { size }(\mathrm{cm})\end{array}$ & Diff. & Margin & V.inv & $\begin{array}{l}\text { Lym/neu. } \\
\text { Inv. }\end{array}$ & Recur. & $\begin{array}{l}\text { Survival } \\
\text { (months) }\end{array}$ & Outcome & $\begin{array}{l}\text { Cause of } \\
\text { death }\end{array}$ \\
\hline I & 51 & $M$ & Present & 1 & 5 & Poor & Positive & $(+)$ & $(-)$ & $\mathrm{IH}, \mathrm{EH}$ & 11 & Died & Cancer \\
\hline 2 & 35 & $M$ & Present & I & 6 & Moderate & Free & $(+)$ & $(-)$ & $\mathrm{IH}$ & 22 & Died & Cancer \\
\hline 3 & 60 & $M$ & Absent & 1 & 4 & Well & Free & $(+)$ & $(-)$ & $(-)$ & 132 & Alive & - \\
\hline 4 & 42 & $M$ & Present & 1 & 6 & Moderate & Free & $(+)$ & $(-)$ & $(-)$ & 104 & Alive & - \\
\hline 5 & 76 & M & Absent & I & 2.5 & Moderate & Free & $(+)$ & $(-)$ & $(-)$ & 84 & Alive & - \\
\hline 6 & 57 & $M$ & Present & 1 & 5.5 & Moderate & Free & $(+)$ & $(-)$ & $(-)$ & 65 & Alive & - \\
\hline 7 & 44 & $M$ & Present & 3 & 3.5 & Well & Free & $(+)$ & $(-)$ & $(-)$ & 60 & Alive & - \\
\hline 8 & 39 & $M$ & Present & 2 & 7.5 & Moderate & Positive & $(-)$ & $(+)$ & $\mathrm{IH}, \mathrm{EH}$ & 17 & Died & Cancer \\
\hline 9 & 46 & $M$ & Absent & I & 8.5 & Poor & Free & $(+)$ & $(-)$ & $(-)$ & 32 & Alive & - \\
\hline 10 & 51 & $M$ & Present & 1 & 7.5 & Poor & Positive & $(+)$ & $(-)$ & $\mathrm{IH}, \mathrm{EH}$ & 4 & Died & Cancer \\
\hline II & 55 & $\mathrm{~F}$ & Absent & 1 & 19 & Moderate & Free & $(+)$ & $(+)$ & $\mathrm{EH}$ & 19 & Alive & - \\
\hline 12 & 50 & $M$ & Absent & 2 & 5 & Moderate & Positive & $(+)$ & $(-)$ & $\mathrm{IH}$ & 16 & Alive & - \\
\hline 13 & 40 & $\mathrm{~F}$ & Absent & 3 & 12 & Well & Positive & $(+)$ & $(-)$ & $\mathrm{IH}$ & 10 & Alive & - \\
\hline 14 & 50 & $M$ & Absent & 1 & 7.5 & Well & Free & $(+)$ & $(-)$ & $\mathrm{IH}$ & 11 & Alive & - \\
\hline 15 & 74 & $M$ & Present & 1 & 2.5 & Moderate & Free & $(-)$ & $(-)$ & $\mathrm{EH}$ & 7 & Alive & - \\
\hline 16 & 47 & $\mathrm{~F}$ & Present & I & 4 & Moderate & Free & $(+)$ & $(-)$ & $(-)$ & 5 & Alive & - \\
\hline 17 & 48 & $M$ & Present & I & 5 & - & - & - & - & - & 2 & Died & Sepsis \\
\hline 18 & 52 & $F$ & Present & I & 5 & - & - & - & - & - & 2 & Died & $\begin{array}{l}\text { Liver } \\
\text { failure }\end{array}$ \\
\hline 19 & 48 & $M$ & Present & I & 2.2 & - & - & - & - & - & 7 & Alive & - \\
\hline
\end{tabular}

Abbreviations: HCC, hepatocellular carcinoma; BDTT, bile duct tumor thrombus; IH, intrahepatic recurrence; EH, extrahepatic recurrence; M, male; F, female; Diff., differentiared; V.inv, venous invasion; Lym/neu. inv., lymphatic/neural invasion; Recur, recurrence.

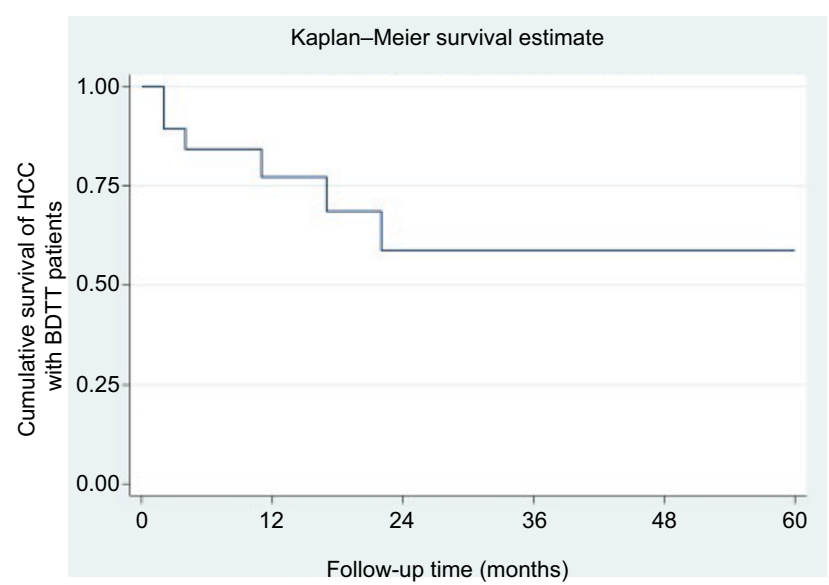

Figure 3 Kaplan-Meier survival analysis for 19 HCC cases with BDTT.

Abbreviations: HCC, hepatocellular carcinoma; BDTT, bile duct tumor thrombus.

beneficial with favorable long-term results. ${ }^{4,8,9,16,23-25}$ On the contrary, there was no chance of palliation or possible cure in patients with advanced tumor infiltration or progressive terminal liver failure. In our series, corrected preoperative diagnosis as having $\mathrm{HCC}$ obstructing the bile duct was high (in almost all patients, 17 of 19 patients), and only one patient was misdiagnosed as hilar CCA, and in another patient, the BDTT diagnosis was determined from the pathological result because there was no suspicious bile duct dilatation from the preoperative $\mathrm{CT}$ of the abdomen.

Curative resection of the tumor improved the outcomes of this type of disease in some previous reports. ${ }^{8,26-31}$ Either preoperative PTBD or endoscopic biliary drainage can be chosen to relieve jaundice with similar procedure-related risk. ${ }^{32-34}$ Preoperative PTBD was performed in five patients without any PTBD-related complications, in our series. Chen et $\mathrm{al}^{4}$ previously reported their experience with $20 \mathrm{HCC}$ patients with BDTT that caused jaundice, in which only two (10\%) patients underwent liver resection. Similarly, Lau et $\mathrm{al}^{27}$ reported a low resectability rate of $18 \%(2 / 11)$. This might be attributed to poor hepatic reserve caused by underlying cirrhosis and obstructive jaundice. In our study, however, 15 of $19(78.9 \%)$ patients underwent a hepatectomy with curative aim and one of 19 patients for palliative aim after appropriate preoperative management, regardless of whether jaundice was present. So, carefully evaluating patient's liver function and future liver remnant were important keys of successful management in HCC with BDTT patients, which could achieve a high rate of $\mathrm{R}_{0}$ resection in $11 / 16(68.7 \%)$ patients. These results would emphasize that biliary tumor thrombi from HCC were not necessarily a contraindication for hepatectomy and do not imply advanced disease.

Intrahepatic metastasis by spreading via the portal vein route was an important mechanism of recurrence. Overall recurrence after hepatectomy occurred in more than half $(9 / 16,56.3 \%)$ of our patients and all with early recurrence within 1 year. Recurrence in one patient was bile duct-related and manifested another episode of obstructive jaundice. Cancer recurring at the choledochotomy site or intraoperative 
implantation appeared to be the likely cause of this condition. Interestingly, there was one patient without portal vein or microscopic venous invasion who also developed both intrahepatic recurrence and pulmonary metastasis. Therefore, this finding implied that HCC invading through the bile duct may have another route of intrahepatic and distant metastasis. A similar result was previously reported by Ikenaga et al. ${ }^{11}$ TACE, direct ethanol injection (DEI), sorafinib, or metastectomy in selective patients are well-established treatments for recurrent intrahepatic HCC and distant metastasis. The pattern of recurrence and modality of treatment after recurrence are shown in Table 3.

In our series, the postoperative 1-year survival rate of patients was $75.0 \%$ with a 1 -year disease-free survival rate of $43.8 \%$. These are better than that of a previous report from Qin et al. ${ }^{3}$ All the five long-term survivors ( $\geq 5$-year survival) received a major liver resection (hemihepatectomy and/or bile duct resection) with the longest disease-free survival of $>11$ years in one patient. This might be attributed to appropriate treatment. In HCC patients with BDTT, shorter survival may be associated with venous or lymphatic invasion, positive margin, poorly differentiated tumor, as well as underlying liver cirrhosis and advanced tumor stage.

\section{Conclusion}

Obstructive jaundice due to biliary thrombus in HCC patients is an uncommon feature but must be kept in mind as one of several differential diagnoses. Bile duct obstruction from tumor thrombus is not necessarily a contraindication for surgery and does not imply advanced disease. Identification of this group of patients is clinically important, because if the appropriate operation is selected, it can offer an opportunity for cure and favorable long-term survival.

\section{Disclosure}

The authors report no conflicts of interest in this work.

\section{References}

1. Huang JF, Wang LY, Lin ZY, et al. Incidence and clinical outcome of icteric type hepatocellular carcinoma. J Gastroenterol Hepatol. 2002; 17(2):190-195.

2. Kojiro M, Kawabata K, Kawano Y, Shirai F, Takemoto N, Nakashima T. Hepatocellular carcinoma presenting as intrabile duct tumor growth: a clinicopathologic study of 24 cases. Cancer. 1982;49(10):2144-2147.

3. Qin LX, Ma ZC, Wu ZQ, et al. Diagnosis and surgical treatments of hepatocellular carcinoma with tumor thrombosis in bile duct: experience of 34 patients. World J Gastroenterol. 2004;10(10):1397-1401.

4. Chen MF, Jan YY, Jeng LB, Hwang TL, Wang CS, Chen SC. Obstructive jaundice secondary to ruptured hepatocellular carcinoma into the common bile duct. Surgical experiences of 20 cases. Cancer. 1994;73(5): 1335-1340.

5. De Gaetano AM, Nure E, Grossi U, et al. Fibrolamellar hepatocellular carcinoma with biliary tumor thrombus: an unreported association. Jpn J Radiol. 2013;31(10):706-712.
6. Sasaki T, Takahara N, Kawaguchi Y, et al. Biliary tumor thrombus of hepatocellular carcinoma containing lipiodol mimicking a calcified bile duct stone. Endoscopy. 2012;44(suppl 2 UCTN):E250-E251.

7. Ise N, Andoh H, Sato T, Yasui O, Kurokawa T, Kotanagi H. Three cases of small hepatocellular carcinoma presenting as obstructive jaundice. HPB (Oxford). 2004;6(1):21-24.

8. Shiomi M, Kamiya J, Nagino M, et al. Hepatocellular carcinoma with biliary tumor thrombi: aggressive operative approach after appropriate preoperative management. Surgery. 2001;129(6):692-698.

9. Satoh S, Ikai I, Honda G, et al. Clinicopathologic evaluation of hepatocellular carcinoma with bile duct thrombi. Surgery. 2000;128(5):779-783.

10. Yeh CN, Jan YY, Lee WC, Chen MF. Hepatic resection for hepatocellular carcinoma with obstructive jaundice due to biliary tumor thrombi. World J Surg. 2004;28(5):471-475.

11. Ikenaga N, Chijiiwa K, Otani K, Ohuchida J, Uchiyama S, Kondo K. Clinicopathologic characteristics of hepatocellular carcinoma with bile duct invasion. J Gastrointest Surg. 2009;13(3):492-497.

12. National Cancer Institute DoMS, Ministry of Public Health, Thailand 2016 [homepage on the Internet]; Available from: http://nci.go.th/. Accessed February 10, 2017.

13. Dindo D, Demartines N, Clavien PA. Classification of surgical complications: a new proposal with evaluation in a cohort of 6336 patients and results of a survey. Ann Surg. 2004;240(2):205-213.

14. Fan ST, Lai EC, Lo CM, Ng IO, Wong J. Hospital mortality of major hepatectomy for hepatocellular carcinoma associated with cirrhosis. Arch Surg. 1995;130(2):198-203.

15. Lee NW, Wong KP, Siu KF, Wong J. Cholangiography in hepatocellular carcinoma with obstructive jaundice. Clin Radiol. 1984;35(2): 119-123.

16. Qin LX, Tang ZY. Hepatocellular carcinoma with obstructive jaundice: diagnosis, treatment and prognosis. World J Gastroenterol. 2003; 9(3):385-391.

17. Nakashima T, Okuda K, Kojiro M, et al. Pathology of hepatocellular carcinoma in Japan. 232 consecutive cases autopsied in ten years. Cancer. 1983;51(5):863-877.

18. Ueda M, Takeuchi T, Takayasu $\mathrm{T}$, et al. Classification and surgical treatment of hepatocellular carcinoma (HCC) with bile duct thrombi. Hepatogastroenterology. 1994;41(4):349-354.

19. Ikeda Y, Matsumata T, Adachi E, Hayashi H, Takenaka K, Sugimachi K. Hepatocellular carcinoma of the intrabiliary growth type. Int Surg. 1997;82(1):76-78.

20. Mok KT, Chang HT, Liu SI, Jou NW, Tsai CC, Wang BW. Surgical treatment of hepatocellular carcinoma with biliary tumor thrombi. Int Surg. 1996;81(3):284-288.

21. Wang HJ, Kim JH, Kim JH, Kim WH, Kim MW. Hepatocellular carcinoma with tumor thrombi in the bile duct. Hepatogastroenterology. 1999;46(28):2495-2499.

22. Spahr L, Frossard JL, Felley C, Brundler MA, Majno PE, Hadengue A. Biliary migration of hepatocellular carcinoma fragment after transcatheter arterial chemoembolization therapy. Eur J Gastroenterol Hepatol. 2000;12(2):243-244.

23. Moon DB, Hwang S, Wang HJ, et al. Surgical outcomes of hepatocellular carcinoma with bile duct tumor thrombus: a Korean multicenter study. World J Surg. 2013;37(2):443-451.

24. Peng SY, Wang JW, Liu YB, et al. Surgical intervention for obstructive jaundice due to biliary tumor thrombus in hepatocellular carcinoma. World J Surg. 2004;28(1):43-46.

25. Qiao W, Yu F, Wu L, Li B, Zhou Y. Surgical outcomes of hepatocellular carcinoma with biliary tumor thrombus: a systematic review. $B M C$ Gastroenterol. 2016;16:11.

26. Lau WY, Leung JW, Li AK. Management of hepatocellular carcinoma presenting as obstructive jaundice. Am J Surg. 1990;160(3): 280-282.

27. Lau W, Leung K, Leung TW, et al. A logical approach to hepatocellular carcinoma presenting with jaundice. Ann Surg. 1997;225(3):281-285.

28. Wu CS, Wu SS, Chen PC, et al. Cholangiography of icteric type hepatoma. Am J Gastroenterol. 1994;89(5):774-777. 
29. Jan YY, Chen MF, Chen TJ. Long term survival after obstruction of the common bile duct by ductal hepatocellular carcinoma. Eur J Surg. 1995;161(10):771-774.

30. Shimada M, Takenaka K, Hasegawa H, et al. Hepatic resection for icteric type hepatocellular carcinoma. Hepatogastroenterology. 1997; 44(17):1432-1437.

31. Tada K, Kubota K, Sano K, et al. Surgery of icteric-type hepatoma after biliary drainage and transcatheter arterial embolization. Hepatogastroenterology. 1999;46(26):843-848.
32. Matsueda K, Yamamoto H, Umeoka F, et al. Effectiveness of endoscopic biliary drainage for unresectable hepatocellular carcinoma associated with obstructive jaundice. J Gastroenterol. 2001;36(3):173-180.

33. Lee JW, Han JK, Kim TK, et al. Obstructive jaundice in hepatocellular carcinoma: response after percutaneous transhepatic biliary drainage and prognostic factors. Cardiovasc Intervent Radiol. 2002;25(3):176-179.

34. Nakayama T, Ikeda A, Okuda K. Percutaneous transhepatic drainage of the biliary tract: technique and results in 104 cases. Gastroenterology. 1978;74(3):554-559.

\section{Publish your work in this journal}

The Journal of Hepatocellular Carcinoma is an international, peerreviewed, open access journal that offers a platform for the dissemination and study of clinical, translational and basic research findings in this rapidly developing field. Development in areas including, but not limited to, epidemiology, vaccination, hepatitis therapy, pathology and molecular tumor classification and prognostication are all considered for publication. The manuscript management system is completely online and includes a very quick and fair peer-review system, which is all easy to use. Visit http://www.dovepress.com/testimonials.php to read real quotes from published authors.

Submit your manuscript here: https://www.dovepress.com/journal-of-hepatocellular-carcinoma-journal 